\title{
Stratospheric Effects of Rocket Exhaust: Heterogeneous Processes
}

\author{
Prepared for: \\ U.S. Air Force Space and Missile Systems Center \\ Environmental Management Branch \\ SMC/AXFV \\ under \\ Contract F09603-95-D-0176-0007 \\ Prepared by: \\ Mario J. Molina \\ Massachusetts Institute of Technology \\ Cambridge, MA 02139 \\ John R. Edwards \\ Daniel Pilson \\ Environmental Management Branch \\ Tyrrel W. Smith, Jr. \\ TRW Space \& Electronics Group
}

Submitted by:

TRW Space \& Electronics Group

30 September 1999 


\title{
Stratospheric Effects of Rocket Exhaust: Heterogeneous Processes
}

\author{
Prepared for: \\ U.S. Air Force Space and Missile Systems Center \\ Environmental Management Branch \\ SMC/AXFV \\ under \\ Contract F09603-95-D-0176-0007 \\ Prepared by: \\ Mario J. Molina \\ Massachusetts Institute of Technology \\ Cambridge, MA 02139 \\ John R. Edwards \\ Daniel Pilson \\ Environmental Management Branch \\ Tyrrel W. Smith, Jr. \\ TRW Space \& Electronics Group \\ Submitted by: \\ TRW Space \& Electronics Group
}

Approved by:

John J. Lamb, Ph.D.

Program Manager

30 September 1999 


\section{Stratospheric Effects of Rocket Exhaust: Heterogeneous Processes}

The focus of this project has been the laboratory investigation of chemical processes involving the effects of particles emitted by solid rocket motors (SRMs) on stratospheric ozone. Emphasis has been placed on the efficiency of the catalytic chlorine activation process occurring on the surface of aluminum oxide particles.

In earlier work (Molina et al., [1996]) we had shown that the following reaction is catalyzed by $\alpha$-alumina surfaces:

$$
\mathrm{ClONO}_{2}+\mathrm{HCl} \rightarrow \mathrm{Cl}_{2}+\mathrm{HNO}_{3}
$$

This reaction is the most important process leading to the transformation of chlorine reservoir species to free chlorine atoms in the polar stratosphere (see WMO [1995]); these atoms efficiently deplete ozone through catalytic cycles. This process occurs efficiently on polar stratospheric cloud particles, thus explaining rapid ozone depletion at high latitudes (Kolb et al., [1995]). At low latitudes the prevailing aerosols consist of concentrated (70 - $80 \%$ weight) sulfuric acid solutions; the reactant $\mathrm{HCl}$ is not soluble in this solutions, and hence the above reaction is not catalyzed by this type of aerosols (Kolb et al., [1995]). The importance of solid particles such as those consisting of alumina is that they may facilitate reaction (1) at mid latitudes, where the background sulfuric acid aerosols are not effective.

The focus of this project has been the laboratory investigation of chemical processes involving the effects of particles emitted by solid rocket motors (SRMs) on stratospheric ozone. Emphasis has been placed on the efficiency of the catalytic chlorine activation process occurring on the surface of aluminum oxide particles.

A major issue remaining to be addressed after our initial investigations is the extent to which our laboratory measurements involving common $\alpha$-alumina samples are applicable to actual alumina particles emitted in the stratosphere by SRMs. The first question related to this issue involves the concentration of reactants, and the second question involves the nature of the surface. To answer these questions it is important to further elucidate at a molecular level the mechanism of the chlorine activation reaction. The hypothesis we made is that the water adsorbed on the surface of the alumina particles promotes the chlorine activation reaction by providing a layer with high affinity for $\mathrm{HCl}$ molecules; to the extent that this hypothesis is correct the detailed properties of the solid surface itself are important only in so far as providing stability for the adsorbed water molecules. 


\section{Heterogeneous chlorine activation reaction mechanism}

We believe that the reaction mechanism is such that the chlorine activation rate is practically independent of the $\mathrm{HCl}$ partial pressure, $\mathrm{P}_{\mathrm{HCl}}$; that is, the rate is large even under stratospheric conditions characterized by small $\mathrm{P}_{\mathrm{HCl}}$ values (about $1-5 \times 10^{-7}$ Torr). However, the mechanism that has been suggested in the literature (particularly for ice and for nitric acid trihydrate surfaces (see review by Peter [1997]) consists of adsorption of $\mathrm{HCl}$ molecules on the alumina surface on specific "active" sites, followed by collisions and reaction of the $\mathrm{ClONO}_{2}$ molecules with the adsorbed $\mathrm{HCl}$. This mechanism predicts that the reaction rate should be proportional to $\mathrm{P}_{\mathrm{HCl}}$, since the surface concentration of this species itself is predicted to be proportional to $\mathrm{P}_{\mathrm{HCl}}$. For the experiments we had carried out in the past, we employed $\mathrm{P}_{\mathrm{HCl}}$ values in the range from $10^{-6}$ to $10^{-5}$ Torr, which is an order of magnitude or more larger than the range typical of the lower stratosphere. Hence, according to the predictions of this particular "active site" mechanism, the reaction probability value under stratospheric conditions would be at most 0.002 , rather than 0.02 , as we originally measured, and chlorine activation on alumina particles would occur at negligible rates in the stratosphere.

The reason for utilizing relatively large $\mathrm{P}_{\mathrm{HCl}}$ values in our earlier work was the lack of sensitivity of the mass spectrometric technique that we originally employed, namely molecular beam sampling with electron impact ionization. For these reasons, in this work we developed a low pressure chemical ionization mass spectrometry (CIMS) method which enabled measurements at much lower $\mathrm{P}_{\mathrm{HCl}}$ values.

\section{Measurement of the reaction probability for the $\mathrm{ClONO}_{2}+\mathrm{HCl}$ reaction}

The experimental configuration is similar to that used previously in our group (e.g., Zhang et al., [1994]), except for the modification to the mass spectrometer apparatus required to operate in the chemical ionization mode. A schematic of the apparatus is presented in Figure 1. The system consists of a low pressure, fast-flow reactor coupled to a differentially pumped mass spectrometer. The double-jacketed Pyrex-glass flowtube is fitted with a movable central injector, through which $\mathrm{ClONO}_{2}$ is introduced while $\mathrm{HCl}, \mathrm{H}_{2} \mathrm{O}$ and $\mathrm{HNO}_{3}$ are added with helium carrier gas from the end of the flowtube for the reaction probability studies. Product and reactant concentrations are measured as a function of injector position under steady state conditions. The experiments were conducted, using a 1.6- $\mathrm{cm}$ i.d. alumina tube with a smooth inner surface inserted into the glass flowtube; a thin Teflon sheet was placed between the two tubes to ensure good thermal contact. The temperature of the flowtube was controlled by circulating cold HCFC-123 through the outer jacket.

Typical reagents concentrations were $[\mathrm{HCl}] \sim 1-15 \times 10^{-7}$ Torr and $\left[\mathrm{ClONO}_{2}\right] \sim 0.8-3 \times 10^{-7}$ Torr, with the total pressure near 1 Torr. The concentration of $[\mathrm{HCl}]$ was about ten-fold excess over $\left[\mathrm{CIONO}_{2}\right]$ to ensure pseudo first order conditions. For some experiments, both $\mathrm{HNO}_{3}$ and $\mathrm{H}_{2} \mathrm{O}$ were added in amounts typical of mid-latitudes of the lower stratosphere ( $\sim 5 \mathrm{ppbv}$ and $\sim 5$ ppmv respectively). The reaction probabilities were determined by monitoring the loss of the reactant $\mathrm{ClONO}_{2}$; the results are summarized in Table 1. 
Pseudo first-order rate constants were determined using a non-linear fitting technique. After correction for the effects of radial diffusion (Brown [1978]), reaction probabilities $(\gamma)$ were determined assuming $\gamma=2 r k / \omega$, where $r$ is the radius of the flow tube, $k$ is the first order rate constant and $\omega$ is the mean thermal velocity of the reactant (Howard [1979]).

As expected, addition of water vapor at pressures in the millitorr range, enough to produce an ice film on the glass tube, yielded reaction probability values which were about an order of magnitude larger, in agreement with our earlier measurements (Molina et al., [1996]) and with literature values (DeMore et al., [1994]). In contrast, measurements performed on 'dry surfaces' (after mild baking and with no water added to carrier gas stream) showed a decrease in $\gamma$ as successive decay curves were collected. Typically $\gamma$ would drop to half the reported value or less after a few runs, indicating the accumulation of the reaction product $\mathrm{HNO}_{3}$ and the removal of remaining water molecules on the alumina surface; however, the low $\gamma$ value could be restored to near its original value simply by humidifying the carrier gas stream with small amounts of water ( $\sim 5 \%$ humidity), presumably by replenishing the lost surface water molecules and by driving of the adsorbed $\mathrm{HNO}_{3}$.

For the CIMS experiments, the negative reagent ion, $\mathrm{SF}_{6}^{-}$, was generated using a corona discharge and then allowed to react with neutral molecules towards the exit of the flow tube. $\mathrm{ClONO}_{2}$ and $\mathrm{HCl}$ were detected as $\mathrm{F}^{\bullet} \bullet \mathrm{ClONO}_{2}(116 \mathrm{emu})$ and $\mathrm{F}^{-} \bullet \mathrm{HCl}$ (55 emu), respectively. The product ions were extracted through a $0.5-\mathrm{mm}$ diameter orifice biased negatively, followed by a set of electrostatic lenses, and further collimated by a $0.5-\mathrm{mm}$ diameter skimmer cone biased positively and located at the entrance of the quadrupole mass analyzer. The use of CIMS allowed us to work with $\mathrm{HCl}$ and $\mathrm{ClONO}_{2}$ concentrations as low as those characteristic of the lower stratosphere $\left(0.5-10 \times 10^{-7}\right.$ Torr). Calibration of the system indicated that the CIMS signal was linear over the range of reactant concentrations employed, from about $5 \times 10^{-8}$ to $2 \times$ $10^{-6}$ Torr.

As shown in Table 1, the reaction probability for the reaction of $\mathrm{ClONO}_{2}$ with $\mathrm{HCl}$ on $\alpha$-alumina surfaces was found to be $\sim 0.02$, in agreement with our earlier results (Molina et al., [1996]) for which we utilized larger reactant concentrations. A major conclusion of this study, as shown explicitly in Table 1, is that the reaction rate is nearly zero order in $\mathrm{HCl}$ for the concentration range covering stratospheric conditions. This result provides a strong indication that the reaction mechanism involves water adsorbed on the alumina surface which solvates $\mathrm{HCl}$, thus explaining the relatively high affinity that this molecule has for the surface. Furthermore, the "active sites" mechanism which predicts that the reaction rate should be linearly proportional to $[\mathrm{HCl}]$ is clearly not supported by the experiments.

\section{Adsorption of water vapor on alumina surfaces}

We investigated the uptake of water vapor by two types of $\alpha$-alumina surfaces: sapphire, and conventional alumina, using essentially the same flowtube technique that we employed for the reaction probability measurements. Early reports by George et al., [1996] suggested that $\alpha$-alumina would loose its surface hydroxyl groups when heated above about $600 \mathrm{~K}$, and that 
water vapor would not react with the surface to regenerate the hydroxyl groups below that temperature. The implication was that alumina particles in the stratosphere would not adsorb water, because they are formed in the SRMs at relatively high temperatures. We countered that the particles would recover their surface $\mathrm{OH}$ groups by reacting with water vapor, but with $\mathrm{OH}$ or $\mathrm{HO}_{2}$ radicals.

Our measurements indicate, however, that even sapphire, which is an $\alpha$-alumina form well known for its extremely inert surface, adsorbs monolayer quantities of water after being heated above $600 \mathrm{~K}$. The measurements were carried out over a temperature range from 230 to $300 \mathrm{~K}$ and a humidity range from $\sim 10$ to $80 \%$. Thus, the mechanism we had proposed for the chlorine activation reaction appears to be applicable, the adsorbed water providing the means for reaction (1) to take place efficiently. Subsequent work by Elam et al., [1998] indicates that the $\mathrm{OH}$ groups will not be permanently lost as readily as initially envisioned; furthermore, Elam et al., [1998] realized that even dehydroxylated alumina adsorbs water, in agreement with our own laboratory results. Hence, the original experiments we had proposed to carry out involving reaction of $\mathrm{OH}$ and $\mathrm{HO}_{2}$ radicals with "clean" alumina surfaces are no longer pertinent: $\alpha$-alumina adsorbs water even after being processed at temperatures well above $900 \mathrm{~K}$, and hence $\alpha$-alumina particles emitted by SRMs are good catalysts for reaction (1).

We should note here that the water uptake experiments by Elam et al., [1998] are complementary to our own; their measurements are carried out under high vacuum conditions, so that only the chemisorbed water is retained, except at temperatures well below those prevailing in the stratosphere (that is, below about $130 \mathrm{~K}$ ). Our measurements are designed to monitor physisorbed water as well, and this is the form that enables the ionic chlorine activation process (reaction 1) to take place.

Our water uptake experiments did reveal differences in the surface activity of sapphire compared to conventional alumina; the results are shown in Figure 2. The uptake by sapphire is reversible, involving only physical adsorption: the water taken up was released by flowing dry carrier gas at room temperature or below. In contrast, the conventional alumina surface chemisorbs some fraction of the water, and at room temperature it only looses upon exposure to dry carrier gas the portion that is physisorbed. We infer, thus, that alumina particles emitted by SRMs will be catalytically active in the stratosphere, because they will be covered by adsorbed water. Surface imperfections and impurities such as chloride or nitrate groups may modify the extent of chemisorbed water, most likely increasing the amount of physisorbed water, since those groups are hydrophilic. That is, adsorbed water will be surely present, enabling the chlorine activation reaction to take place.

\section{Effect of sulfuric acid vapor on the alumina surface}

We investigated experimentally the effect of $\mathrm{H}_{2} \mathrm{SO}_{4}$ vapor on alumina surfaces by exposing alumina particles in a chamber containing a liquid sulfuric acid receptacle for periods of up to several days. The chamber was evacuated in order to prevent gas diffusion limitations. The acidity of the aluminum surface was subsequently investigated by means of sensitive $\mathrm{pH}$ indicators; no evidence of acid transfer to the aluminum surface could be established. More 
definitive experiments involving actual reaction probability measurements for chlorine activation would need to be carried out to establish more directly the extent of surface passivation; however, our preliminary experiments indicate that sulfuric acid is not readily taken up by the alumina surface. Also, the accommodation coefficient for sulfuric acid molecules on alumina surfaces in the presence of water vapor remains to be determined; based on the preliminary experiments described here the coefficient to have a value smaller than 0.1 .

We also investigated theoretically the time required for alumina particles in the stratosphere to be coated by sulfuric acid. The $\mathrm{H}_{2} \mathrm{SO}_{4}$ vapor pressure of aqueous sulfuric acid aerosols in the lower stratosphere is extremely low $\left(<10^{-3}\right.$ Torr $)$; if equilibrium were to be maintained, only a negligible amount of sulfuric acid vapor would be transferred to the alumina particle surfaces. However, early modeling calculations by Turco et al., [1982] indicate that there is a large supersaturation with respect to $\mathrm{H}_{2} \mathrm{SO}_{4}$ vapor, and hence the possibility of significant condensation on the particle surface needs to be taken into account. The in-situ measurements by Arnold et al., [1981] report $\mathrm{H}_{2} \mathrm{SO}_{4}$ partial pressures around $10^{-5}$ Torr between 23 and $27 \mathrm{~km}$ altitude; unfortunately, there are no measurements at lower altitudes, which is the region of interest for the chlorine activation processes discussed in this report. For our calculations we have assumed $\mathrm{a}_{2} \mathrm{SO}_{4}$ partial pressures around $10^{-5}$ Torr at these lower altitudes, whereas the equilibrium vapor pressures fall in the range from $10^{-3}$ to $10^{-4}$ Torr; for the higher altitudes we used the partial pressures given by Arnold et al., [1981]. We carried out the calculations using the well-established mass transfer equations to aerosol droplets (Kolb et al., [1995]) assuming a range of values for the accommodation coefficient; the results, shown in Figure 3, indicate that significant surface passivation will occur on a time scale of months only if the accommodation coefficient approaches unity. For smaller accommodation coefficient values the time increases accordingly. Considering the nature of the water layers adsorbed on the alumina surface we estimate that the accommodation coefficient will be 0.1 or less; laboratory measurements would need to be carried out to establish the actual value. As can be seen in Figure 3, the estimated time required for $\mathrm{H}_{2} \mathrm{SO}_{4}$ to form a monolayer on the surface of the alumina particles in the lower stratosphere is of the order of 8 months, assuming an accommodation coefficient of 0.1 . Of course, if the actual $\mathrm{H}_{2} \mathrm{SO}_{4}$ partial pressures at the lower altitudes have values below $10^{5}$ Torr the required times would increase accordingly.

\section{Conclusions}

In this project we measured the reaction probability $\gamma$ for the reaction of $\mathrm{ClONO}_{2}$ with $\mathrm{HCl}$ on alumina surfaces. The result is $\gamma=0.02$ under conditions similar to those which would be encountered at mid-latitudes in the lower stratosphere; it is in very good agreement with our earlier measurements on alumina and on glass surfaces conducted with larger reactant concentrations. We conclude that the reaction is nearly zero order in $\mathrm{HCl}$, and that the mechanism does not depend on the detailed nature of the refractory oxide surface itself; it depends to a larger extent on the presence of absorbed water layers.

Our calculations indicate that a significant fraction of the injected alumina surface area will be catalytically active and will remain unaffected in the stratosphere by sulfuric acid vapor; we estimate that the time required for the alumina particles to be covered by a monolayer of 
sulfuric acid is of the order of 8 months, assuming an accommodation coefficient of 0.1 . Furthermore, coalescence with stratospheric sulfuric acid aerosols will most likely be unimportant for the alumina particles larger than $\sim 0.1 \mu \mathrm{m}$ in diameter before they settle out of the stratosphere.

Our earlier preliminary conclusion was that the ozone depletion potential of SRMs is higher than that predicted on the basis of chlorine emissions alone, especially at mid-latitudes in the lower stratosphere, where catalytic chlorine activation by background sulfuric acid aerosols is very inefficient. Jackman et al., [1998] carried out detailed stratospheric modeling calculations of ozone depletion caused by SRMs using our preliminary reaction probability measurement for reaction (1) on alumina particles $(\gamma=0.02)$. Their calculations indicate that the effect on the annually averaged global total ozone is a decrease of $0.025 \%$ by the year 1997 ; about one third of this decrease results from the SRM-emitted alumina and the remaining two thirds result from the SRM-emitted hydrogen chloride. The results presented here validate the reaction probability values employed by Jackman et al., [1998].

Some of the results presented in this report have already appeared in the literature (see Molina et al., [1996]).

\section{References}

Arnold, F., R. Fabian, and W. Joos, "Measurements of height variation of sulfuric acid vapor concentrations in the stratosphere," Geophys. Res. Lett., 8, 293-296, 1981.

Brown, R.L., "Tubular flow reactors with first order kinetics," J. Res. Nat. Burl Stand., 83, 1-8, 1978.

DeMore, W. B., D. M. Golden, R. F. Hampson, C. J. Howard, C. E. Kolb, M. J. Kurylo, M. J. Molina, A. R Ravishankara and S. P. Sander, "Chemical Kinetics and Photochemical Data for Use in Stratospheric Modeling," JPL Publ. 94-26, Evaluation Number 11, 1994.

George, S. M., M. A. Tolbert, M. A. Cameron and C. E. Nelson, "Hydroxylation and dehydroxylation of aluminum oxide surfaces," paper presented at the symposium on The Impact of Rockets on the Stratosphere, Redondo Beach, California, May 1996.

Elam, J. W., C. E. Nelson, M. A. Cameron, M. A. Tolbert, and George, S. M., "Adsorption of $\mathrm{H}_{2} \mathrm{O}$ on single crystal $\alpha-\mathrm{Al}_{2} \mathrm{O}_{3}(001)$ surfaces modeling rocket exhaust particles," submitted for publication to J. Phys. Chem., 1998.

Jackman, C. H., D. B. Considine and E. L. Fleming, "A global modeling study of solid rocket aluminum oxide emission effects on stratospheric ozone," Geophys. Res. Lett., 25, 907-910, 1998. 
Howard, C. L., "Kinetic measurements using flow tubes," J. Phys. Chem., 83(1), 3-9, 1979.

C.E. Kolb, D.R. Worsnop, M. S. Zahniser, P. Davidovits, C. F. Keyser, M. T. Leu, M. J.

Molina, D. R. Hanson, A. R. Ravishankara, L.R. Williams, and M. A. Tolbert, "Laboratory studies of atmospheric heterogeneous chemistry," In Current Problems and Progress in Atmospheric Chemistry, edited by J. R. Barker, in Advances in Physical Chemistry Series, Vol. 3, 771-875, World Scientific Publishing, 1995.

Molina, M. J., Spencer, D. D., L. T. Molina, and R. F. Meads, "Chlorine Activation on Alumna and Glass Surfaces," paper presented at the symposium on The Impact of Rockets on the Stratosphere, Redondo Beach, California, May, 1996.

Molina, M. J., L. T. Molina, R. Zhang, R. F. Meads, and D. D. Spencer, "The reaction of $\mathrm{ClONO}_{2}$ with $\mathrm{HCl}$ on aluminum oxide," Geophys. Res. Lett., 24, 1619-1622, 1997.

Peter, T., Microphysics and heterogeneous chemistry of polar stratospheric clouds, Annul Rev. Phys. Chem., 48, 785-822, 1997.

Turco, R.P., O.B. Toon, J.B. Pollack, R.C. Whitten, J.G. Poppoff and P. Hamill, "Stratospheric aerosol modification by supersonic transport and space shuttle operations - climate implications," J. Appl. Meteor., 19, 78-89, 1980.

Zhang, R., J.T. Jayne and M.J. Molina, "Heterogeneous interactions of $\mathrm{ClONO}_{2}$ and $\mathrm{HCl}$ with sulphuric acid tetrahydrate: Implications for the stratosphere," J. Phys. Chem., 98, 867-874, 1994.

WMO, Scientific Assessment of Ozone Depletion: 1994, World Meteorological Organization, Global Ozone Research and Monitoring, Project-Report No. 37, 1995. 
Table 1. Reaction probabilities for $\mathrm{ClONO}_{2}+\mathrm{HCl}$ on an $\alpha$-alumina flow tub surface using $\mathrm{CIMS}^{\mathrm{a}}$

\begin{tabular}{|c|c|c|c|}
\hline Temperature (K) & $\mathbf{P}_{\mathrm{HCl}}$ (Torr) & $\mathbf{P}_{\mathrm{ClONO} 2}$ (Torr) & $\gamma$ \\
\hline $221.3^{b}$ & $1.3 \times 10^{-6}$ & $1.43 \times 10^{-7}$ & 0.0167 \\
\hline $220.7^{b}$ & $1.23 \times 10^{-6}$ & $2.6 \times 10^{-7}$ & 0.0179 \\
\hline $220.6^{b}$ & $9.33 \times 10^{-7}$ & $2.6 \times 10^{-7}$ & 0.0221 \\
\hline $215.5^{b}$ & $6.93 \times 10^{-7}$ & $2.5 \times 10^{-7}$ & 0.0161 \\
\hline $213.2^{b}$ & $1.13 \times 10^{-6}$ & $2.6 \times 10^{-7}$ & 0.0256 \\
\hline $211.4^{b}$ & $6.23 \times 10^{-7}$ & $1.6 \times 10^{-7}$ & 0.0194 \\
\hline $208.0^{b}$ & $7.13 \times 10^{-7}$ & $2.6 \times 10^{-7}$ & 0.0126 \\
\hline \multicolumn{4}{|c|}{${ }^{\mathrm{b}} \gamma($ average $)=0.0180 \pm 0.0043(1 \sigma)$} \\
\hline $222.9^{c}$ & $8.83 \times 10^{-7}$ & $2.6 \times 10^{-7}$ & 0.0191 \\
\hline $213.8^{\mathrm{c}}$ & $3.43 \times 10^{-7}$ & $8.7 \times 10^{-8}$ & 0.0138 \\
\hline $211.4^{\mathrm{c}}$ & $6.93 \times 10^{-7}$ & $1.9 \times 10^{-7}$ & 0.0280 \\
\hline \multicolumn{4}{|c|}{${ }^{c} \gamma($ average $)=0.0203 \pm 0.0072(1 \sigma)$} \\
\hline
\end{tabular}

${ }^{a}$ Experimental conditions: $\mathrm{P}_{\mathrm{He}}=2.5$ Torr, flow velocity $=2800 \mathrm{~cm} \mathrm{~s}^{-1}$.

Each $\gamma$ value is an average of more than two measurements.

${ }^{b}$ Measurements performed in the absence of $\mathrm{H}_{2} \mathrm{O}$ vapor

${ }^{\mathrm{c}}$ Measurements performed in the presence of water vapor at a partial pressure of $1.9 \times 10^{-4} \mathrm{Torr}$ 


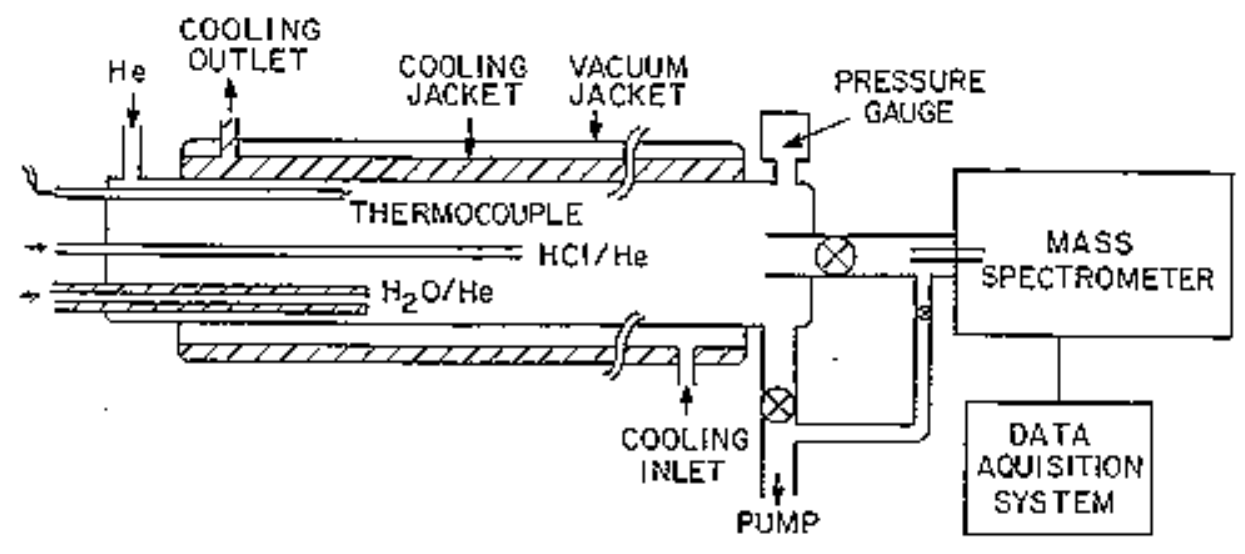

Figlise 1. Schematic of the flowtube apparatus employed for the reaction probarility and surface uptake roeastrefients. The chlorine nürthe decys are monitored by introducing this species through the central movenble injector, with HCl and $\mathrm{H}_{2} \mathrm{O}$ beingr introduecd upstrean together with the cartier gas. For the surfaee uptake experiments the specjes of interest is introdueed through the movealle injector positioned initially towards the flow tule exit; the mass spetrometcr signal for this spccies is then wonjored as the injechr is rapidly pufled back to expose a portiont of the temperature-contralled Gowtube surface. 

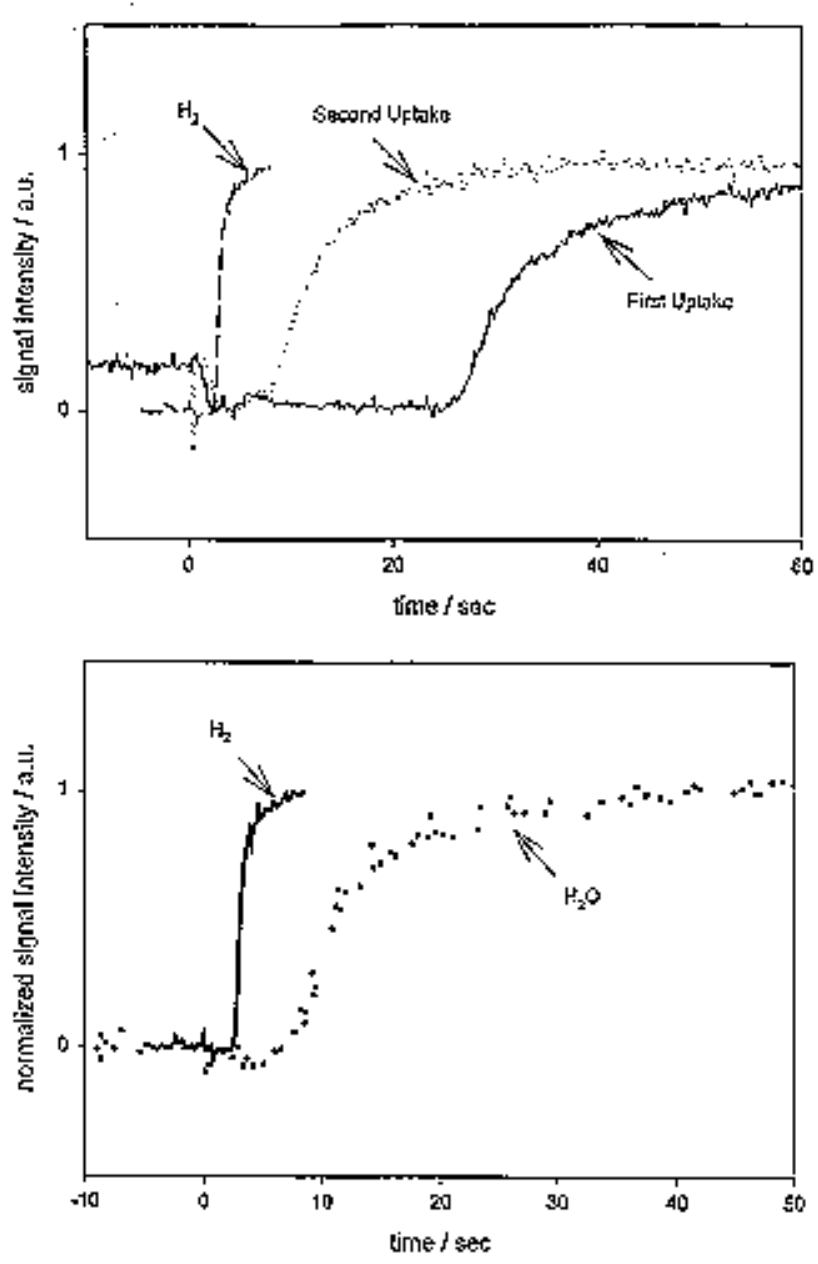

Figute 2: Uptake of water on o-alumina at $300 \mathrm{~K}$ and standard prossine after annealing the alumina at $900 \mathrm{~K}$. Brakthrough signals mokitond at $300 \mathrm{~m}$ Ton partial pressure of water and 10 socm He cartier gas low. Also shown is the jeference oxperiment uning $\mathrm{H}_{1}$ jnstend of $\mathrm{H}_{2} \mathrm{O}$ as a probe gis.

(a) Conmercial or-alumina (Cerac, Inc) Particle size: 0.15 to $0.2 \mathrm{~mm}$; column length: 2 crir; cstimated surfice aped $3.6 \mathrm{~cm}^{2}$. The first and subsequant uptakes contespond to $52 \times \mathrm{I0}^{16}$ molecules and $1.5 \times 10^{15}$ molecules, respectively.

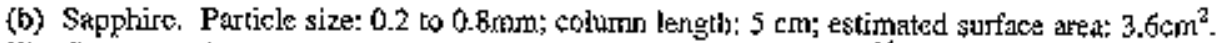
The first and subsequent uptakes are equal and concspond to $1.9 \times \mathrm{I0}^{\text {th }}$ inolecules. 


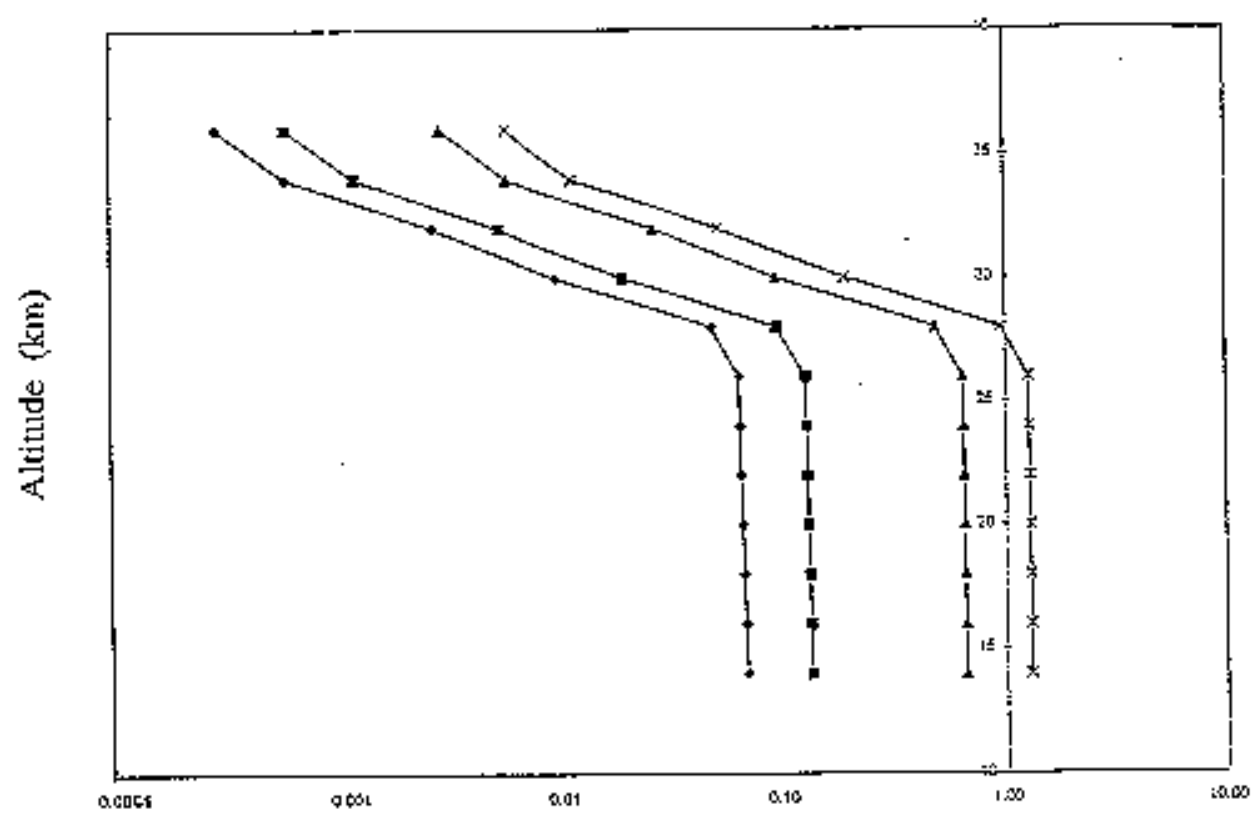

Time (years)

Figure 3. Calculated time requircd for $0.1 \mu \mathrm{m}$ diameter particles to be coated with a monolayer of sulfuric actid. The partial pressire of $\mathrm{H}_{2} \mathrm{SO}_{4}$ above $23 \mathrm{~km}$ is taken from Amold et al. (1981); below $23 \mathrm{~km}$ it is assuned to hawe a value of $-10^{5} \mathrm{Tom}$, which is far abowe the thennodyuthic eguiliberun value. The time (in years) is ploter as a function of altitude (in $\mathrm{km}$ ) with the aeconnolation coefficient as a parameter with the following values: crosses, 0.05; Iriandicles, 0. I; squares, 0.5; diamonds, 1.0 . 